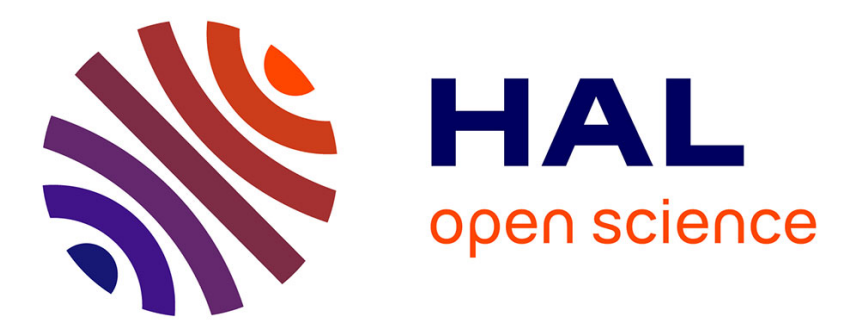

\title{
Novel NaI improved Ge-Ga-Te far-infrared chalcogenide glasses
}

Ci Cheng, Xunsi Wang, Tiefeng Xu, Lihong Sun, Qingde Zhu, Zhanghao Pan, Qiuhua Nie, Peiqing Zhang, Yuehao Wu, Shixun Dai, et al.

\section{- To cite this version:}

Ci Cheng, Xunsi Wang, Tiefeng Xu, Lihong Sun, Qingde Zhu, et al.. Novel NaI improved GeGa-Te far-infrared chalcogenide glasses. Infrared Physics and Technology, 2015, 72, pp.148-152. 10.1016/j.infrared.2015.07.024 . hal-01188223

HAL Id: hal-01188223

https://hal-univ-rennes1.archives-ouvertes.fr/hal-01188223

Submitted on 16 Sep 2015

HAL is a multi-disciplinary open access archive for the deposit and dissemination of scientific research documents, whether they are published or not. The documents may come from teaching and research institutions in France or abroad, or from public or private research centers.
L'archive ouverte pluridisciplinaire HAL, est destinée au dépôt et à la diffusion de documents scientifiques de niveau recherche, publiés ou non, émanant des établissements d'enseignement et de recherche français ou étrangers, des laboratoires publics ou privés. 


\title{
Novel NaI improved Ge-Ga-Te far-infrared chalcogenide glasses
}

\author{
Ci Cheng ${ }^{1}$, Xunsi Wang ${ }^{1 *}$, Tiefeng Xu ${ }^{1}$, Qingde Zhu ${ }^{1}$, Lihong Sun ${ }^{1}$, Zhanghao Pan ${ }^{1}$, \\ Qiuhua Nie ${ }^{1}$, Peiqing Zhang ${ }^{1}$, Yuehao $\mathrm{Wu}^{1}$, Shixun Dai ${ }^{1}$, Xiang Shen ${ }^{1}$, Xianghua Zhang ${ }^{2}$ \\ ${ }^{1}{ }^{1}$ Laboratory of Infrared Material and Devices, The Research Institute of Advanced Technologies, Ningbo University, Ningbo, Zhejiang \\ 315211, China) \\ ( ${ }^{2}$ Laboratory of Glasses and Ceramics, UMR 6226 CNRS-University of Rennes 1, Rennes Cedex 135042, France)
}

\begin{abstract}
In this study, a novel Te-based glass system was investigated. Some properties of Ge-Ga-Te-NaI chalcogenide glasses such as physical, thermal and optical transmitting were discussed. XRD patterns show this glass system with best amorphous state can dissolve NaI content as much as 35 at.\%. And a lowest cut-off wavelength of glass samples is $1645 \mathrm{~nm}$ which is the smallest wavelength among the reported Te-based glasses doping with alkali-halide. DSC curves indicate that all the glass samples have good thermal stabilities $\left(\Delta \mathrm{T}>100^{\circ} \mathrm{C}\right)$ and the highest $\Delta \mathrm{T}$ value corresponding to $\left(\mathrm{Ge}_{15} \mathrm{Ga}_{10} \mathrm{Te}_{75}\right)_{85}(\mathrm{NaI})_{15}$ glass is $120^{\circ} \mathrm{C}$ which is $8^{\circ} \mathrm{C}$ greater than that of Ge-Ga-Te host glass. The infrared spectra manifest Ge-Ga-Te-NaI chalcogenide glasses have a wide infrared transmitting window between $1.6 \mu \mathrm{m}$ and $25 \mu \mathrm{m}$. Consequently, Ge-Ga-Te-NaI glasses can be a candidate material for far infrared optic imaging and bio-sensing applications.
\end{abstract}

Keywords: chalcohalide glass; thermal property; infrared spectra

\section{Introduction}

To explore the existence of life in exoplanet, many projects have been carried out. Particularly, the Darwin project conducted by European Space Agency is the most popular among these projects[8]. This project aims at detecting $\mathrm{CO}_{2}$ molecule which is produced by living organisms. At the same time, the detection of $\mathrm{CO}_{2}$ gas content in the earth's atmosphere is also of interest in environmental science such as global warming. All this applications are located at the optical spectra of middle and far infared.

Chalcogenide glasses have attracted great attention in the infrared material and device filed due to its excellent infrared transmission characteristics over the past decades. Apart from oxygen element, chalcogenide glasses which contain sulfur, selenium or tellurium elements have many excellent features such as lower phonon energy, outstanding transmission properties, high linear and nonlinear refractive index and high photosensitivity etc. [1,2] Compared to traditional silica based glasses, chalcogenide glasses have a larger transparency window which can cover from visible region to the far infrared depending on the glass composition [3-6]. Nevertheless, the transmission of sulfur- or selenium-based glasses is limited to $12 \mu \mathrm{m}$ or $14 \mu \mathrm{m}$ respectively. Thus, developing the glass fibers which transmission are up to $20 \mu \mathrm{m}$ are necessary. However, S- and Se-based glass fibers are cannot meet the requirement because the very specific $\mathrm{CO}_{2}$ broad absorption band is located around $15 \mu \mathrm{m}$. Since the atomic mass of Te atom is larger than $\mathrm{S}$ and $\mathrm{Se}$ atoms, according to the principle of phonon vibration spectrum[7], the far infrared cut-off wavelength of Te-based glass is larger than S- and Se-based glasses. Hence, Te-based glasses can better meet the requirement of far infrared applications. So the only way is to prepare Te-based

\footnotetext{
* Corresponding author. Fax: +86 57487600947.

E-mail address: xunsiwang@siom.ac.cn (X.Wang).
} 
glasses and then drawn into fibers. Due to its strong metallic and low dimensionality of glass framework, traditional Te-based glasses such as $\mathrm{Te}-\mathrm{X}(\mathrm{Cl}, \mathrm{Br}, \mathrm{I})$ have weak mechanical and low thermal characters. Thus, these glasses are not the candidate material for fibers. Then, the Ge-As-Te, the Ge-Te-I and the Ge-Ga-Te glass systems have investigated recently [9-11]. Although these glasses have better mechanical and thermal properties than Te-X glasses, they have many detects. The Ge-As-Te glasses contain the element of "As" that will pollute the environment seriously. The Ge-Te-I glasses are prone to volatilize because of I element contained. The maximum $\Delta \mathrm{T}$ value (the difference between the glass transition temperature $\mathrm{Tg}$ and the glass onset crystallization temperature $\mathrm{Tx}$ ) of Ge-Ga-Te glass is only $113^{\circ} \mathrm{C}$, the $\Delta \mathrm{T}$ value is still too small to ensure the glasses would not crystalize when they are drawn into optical fibers or shaped into lenses. Wang et al. proposed that halide doped into Te-based glasses can open up the glass network and then enlarge the glass formation, improve the chemical stability as well as the ability of anti-crystal[12]. Therefore, halide, which are not easily volatile, are added into Ge-Ga-Te glass may be able to improve the thermal properties of chalcogenide glasses[13]. So far, there is still no report about the investigation of $\mathrm{NaI}$ doped into Ge-Ga-Te glasses.

In this study, we discussed a new family of Te-based chalcogenide glass. By adding different molecular weight of $\mathrm{NaI}$ content, some glass properties such as thermal and infrared transmission etc. were investigated. There is no other comprehensive report about the influence of $\mathrm{NaI}$ on the structure and chemical or physical properties about Ge-Ga-Te-NaI glasses. The optical and thermal properties were discussed by the help of Fourier Transform infrared spectroscopy (FTIR) and DSC instruments.

\section{Experiments and Testing Methods}

The raw materials $\mathrm{Ge}, \mathrm{Ga}, \mathrm{Te}$ with $5 \mathrm{~N}$ purity and $\mathrm{NaI}(4 \mathrm{~N})$ were chosen to prepare for a series of Ge-Ga-Te based glass samples. The preparation method was adopted with conventional vaccum melt-quenching process. The raw materials were weighed accurately and then mixed into a silica tube which was sealed under the pressure of $1 \times 10^{-3} \mathrm{~Pa}$. The tubes were then placed in rocking furnaces and heated at $850 \mathrm{~h}$ for 15 hours to homogenize the mixtures. After that, the temperature of furnaces decreased to 730 before ampoules quenched in ice water. Afterwards, the ampoules were annealed at $10^{\circ} \mathrm{C}$ below $\mathrm{Tg}$ in the prepared furnaces. The glass rods were taken out from the silica tubes and then were cutted into discs. The thickness of these glass disk samples were recorded in the Table 2. Finally, the glass discs were polished for testing.

The densities of glass samples were calculated by the Archimedes' principle (with an accuracy of $\pm 0.001 \mathrm{~g} / \mathrm{cm}^{3}$ ). In order to confirm the amorphous state, the X-ray powder diffraction apparatus by German Bruker D2 using $\mathrm{CuK} \alpha$ radiation were performed. Glass transition temperature ( $\mathrm{Tg}$ ) and onset crystallization temperature (Tx) of glass samples were measured by Differential Scanning Calorimetry (DSC). The heating temperature is range from 50 to $350^{\circ} \mathrm{C}$ with a heating rate of $10^{\circ} \mathrm{C} / \mathrm{min}$ by a TAQ2000 thermal analyzer. The infrared transparency windows were obtained by using Nicolet 380 Fourier transforming infrared spectroscopy in the range of $4000-400 \mathrm{~cm}^{-1}$. The visible to near infrared transmission spectra was acquired by means of Perkin-Elmer Lambda 950 spectrophotometer which the wavelength range is from 400 to 2500 $\mathrm{nm}$. The Raman spectra were gathered using a Renishaw Raman microscope with an Ar+ ion laser in the range of $80-800 \mathrm{~cm}^{-1}$. The spectral resolution was set to $1 \mathrm{~cm}^{-1}$. All optical testing procedures were performed at room temperature. 


\section{Results and Discussions}

\subsection{Physical and thermal properties}

A series of $\left(\mathrm{Ge}_{15} \mathrm{Ga}_{10} \mathrm{Te}_{75}\right)_{100-\mathrm{x}}(\mathrm{NaI})_{\mathrm{x}}$ glass samples were prepared successfully with $\mathrm{x}=0,5$, $10,15,20,25,30,35$. The densities of all glass samples are listed in Table 1. With content of NaI increasing, the densities of glass samples decreased from $5.735 \mathrm{~g} \cdot \mathrm{cm}^{-3}$ to $5.387 \mathrm{~g} \cdot \mathrm{cm}^{-3}$ gradually. As that the glass density is determined by the elemental relative atomic mass and the packing efficiency of atoms[14]. The relative atomic mass of $\mathrm{NaI}$ is 150 , smaller than that of $\mathrm{GeTe}_{4}$ (585) and $\mathrm{GaTe}_{3}$ (454). With $\mathrm{NaI}$ doped into Ge-Ga-Te glass, $\mathrm{GeTe}_{4}$ and $\mathrm{GaTe}_{3}$ units reduced, and the packing efficiency of atoms was lower. Thus, the densities of $\left(\mathrm{Ge}_{15} \mathrm{Ga}_{10} \mathrm{Te}_{75}\right)_{100-\mathrm{x}}(\mathrm{NaI})_{\mathrm{x}}$ glass samples decreased along with $\mathrm{NaI}$ content increasing. On the contrary, the average molar volume increased. This can be calculated by the following formula (1).

$$
V_{m}=\frac{\sum_{i} M_{i}}{\rho},
$$

where $M_{i}$ is the molar mass of glass samples ( $M_{i}=A_{i} B_{i}, A_{i}$ : the molar concentration; $B_{i}$ : the molecular weight of glass composition; $\rho$ : the density of glass sample). The specific values are presented in Table 1.

Table 1 Physical and thermal parameters of $\left(\mathrm{Ge}_{15} \mathrm{Ga}_{10} \mathrm{Te}_{75}\right)_{100-\mathrm{x}}(\mathrm{NaI})_{\mathrm{x}}$ glass samples

\begin{tabular}{cccccc}
\hline $\begin{array}{c}\mathbf{X} \\
\mathbf{a t} \boldsymbol{\%}\end{array}$ & $\begin{array}{c}\boldsymbol{\rho} \\
\mathbf{g} \cdot \mathbf{c m}^{-3}\end{array}$ & $\begin{array}{c}\mathbf{V}_{\mathbf{m}} \\
\mathbf{m}^{3} \cdot \mathbf{m o l}^{-1}\end{array}$ & $\begin{array}{c}\mathbf{T g} \\
{ }^{\circ} \mathbf{C}\end{array}$ & $\begin{array}{c}\mathbf{T x} \\
{ }^{\circ} \mathbf{C}\end{array}$ & $\begin{array}{c}\Delta \mathbf{T} \\
{ }^{\circ} \mathbf{C}\end{array}$ \\
\hline 0 & 5.735 & 19.869 & 172 & 284 & 112 \\
5 & 5.512 & 21.000 & 177 & 285 & 108 \\
10 & 5.492 & 21.405 & 171 & 288 & 117 \\
15 & 5.467 & 21.832 & 168 & 288 & 120 \\
20 & 5.446 & 22.248 & 171 & 284 & 113 \\
25 & 5.420 & 22.687 & 173 & 283 & 110 \\
30 & 5.402 & 23.096 & 176 & 281 & 105 \\
35 & 5.387 & 23.495 & 176 & 278 & 102 \\
\hline
\end{tabular}

\subsection{Analysis of amorphous state}

To verify the amorphous state of glass samples, XRD were performed on $\left(\mathrm{Ge}_{15} \mathrm{Ga}_{10} \mathrm{Te}_{75}\right)_{100-\mathrm{x}}(\mathrm{NaI})_{\mathrm{x}}$ glass samples. The XRD diffraction patterns are presented in Fig. 1. Here, all curves were smooth while peaks exhibited width and dispersion. All glass samples showed excellent amorphous properties. Ge-Ga-Te host glass can dissolve 35 at.\% NaI contents eventually. 


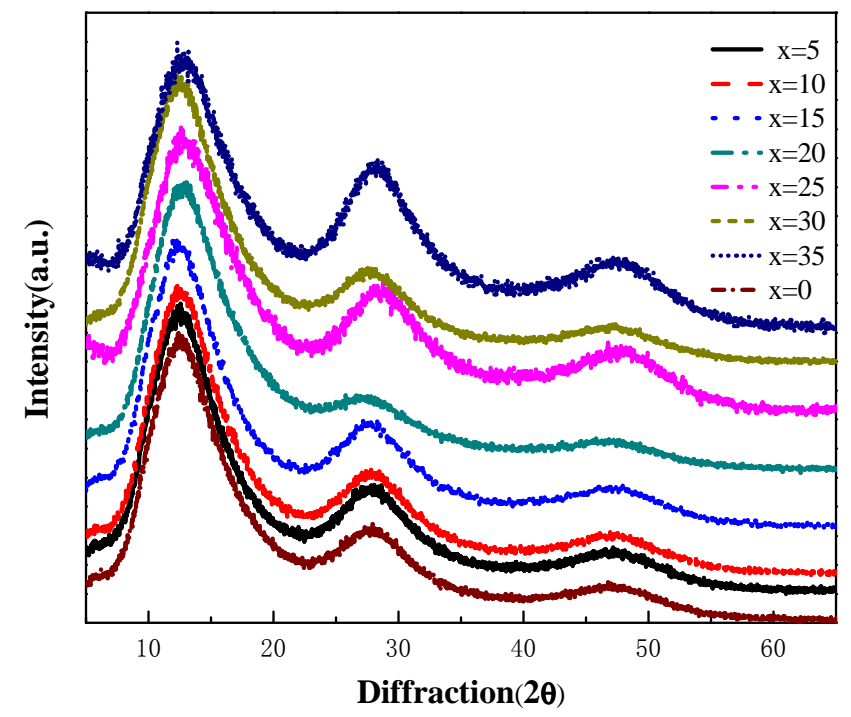

Fig. 1 XRD patterns of Ge-Ga-Te-NaI glass samples

\subsection{Thermal properties}

Thermal properties of these glass samples were tested by DSC instrument. DSC curves of all glass samples are showed in Fig. 2. The glass transition temperature $\mathrm{Tg}$ and the glass onset crystallization temperature Tx can be obtained from the curves. The difference between $\mathrm{Tg}$ and $\mathrm{Tx}$ is defined as $\Delta \mathrm{T}$ which is always used to evaluated the thermal performance of glass samples. And the specific values of $\mathrm{Tg}$, $\mathrm{Tx}$ and $\Delta \mathrm{T}$ are recorded in Table 1 . Here, $\left(\mathrm{Ge}_{15} \mathrm{Ga}_{10} \mathrm{Te}_{75}\right)_{85}(\mathrm{NaI})_{15}$ glass sample whose $\Delta \mathrm{T}$ value is $120^{\circ} \mathrm{C}$ possesses superior thermal properties than other glass samples. Compared to that of $\mathrm{Ge}_{15} \mathrm{Ga}_{10} \mathrm{Te}_{75}$ glass, the $\Delta \mathrm{T}$ value of $\left(\mathrm{Ge}_{15} \mathrm{Ga}_{10} \mathrm{Te}_{75}\right)_{85}(\mathrm{NaI})_{15}$ glass was increased by $8^{\circ} \mathrm{C}$. This may be resulted from the effect of I atoms which trapped the metallic electrons from $\mathrm{Te}$ atoms and formed strong Te-I bonds. With Te-Te bonds reducing, the tendency of Te microcrystal formation decreased. Thus, the stability of the chalcogenide glasses against crystallization was improved. When the content of $\mathrm{NaI}$ is from 5 to 15 at.\%, the $\Delta \mathrm{T}$ of glass samples increased gradually. But, $\Delta \mathrm{T}$ values decreased when $\mathrm{NaI}$ content surpassed 15 at. $\%$, as that it is too much for resovalation in the $\mathrm{Ge}_{15} \mathrm{Ga}_{10} \mathrm{Te}_{75}$ glass matrix. The variation tendency of $\mathrm{Tg}$ and Tx are shown in Fig. 3. As a consequence, it proves that a proper content of NaI doping into chalcogenide glasses can improve the thermal properties of matrix glass. What's more, the $\Delta \mathrm{T}$ values of all glass samples are above $100^{\circ} \mathrm{C}$. It indicates that $\left(\mathrm{Ge}_{15} \mathrm{Ga}_{10} \mathrm{Te}_{75}\right)_{100-\mathrm{x}}(\mathrm{NaI})_{\mathrm{x}}$ glasses keep good thermal characteristics which are potential for being drawn into fibers. 


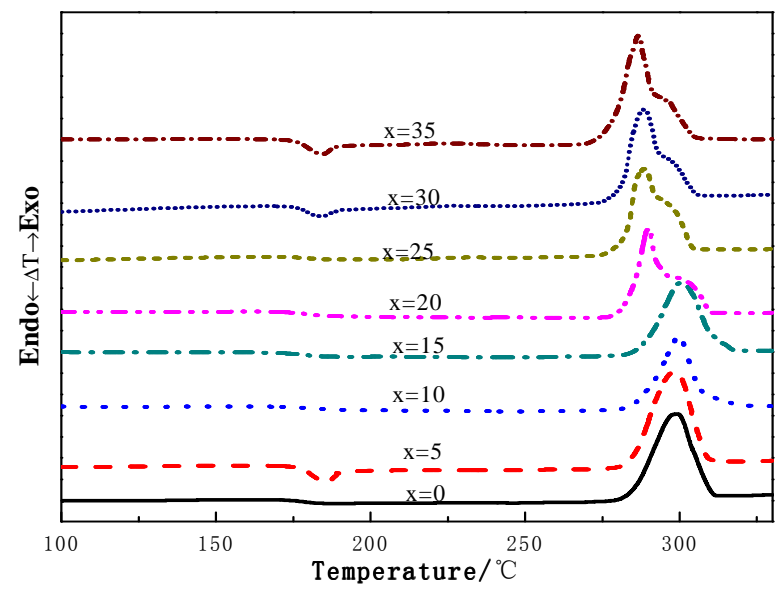

Fig. 2 The DSC curves of Ge-Ga-Te-NaI glass samples

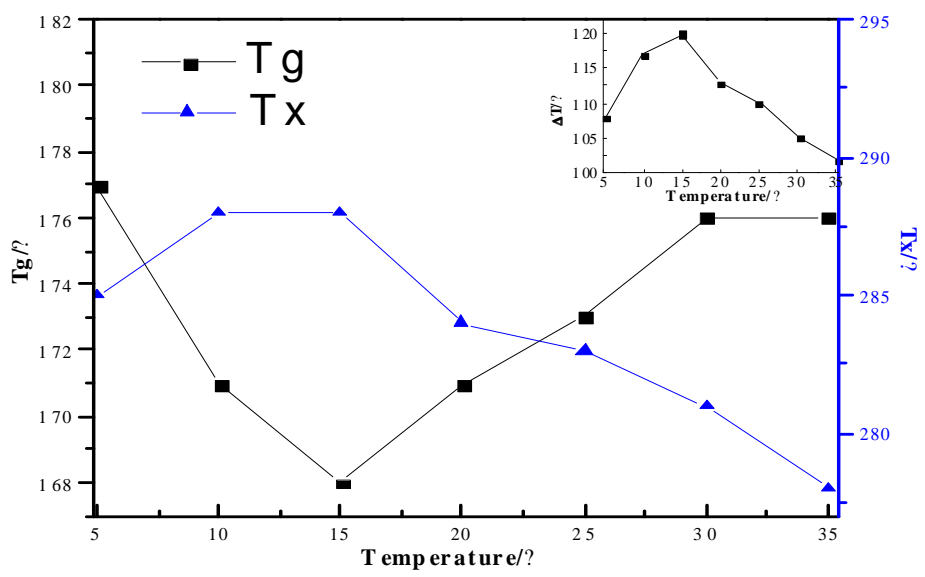

Fig. $3 \mathrm{Tg}$ and Tx of Ge-Ga-Te-NaI glass samples

\subsection{Raman spectra analysis}

Structure comfirmation for the glass is one important aspect for glass researching. The spectrum signature of glass' matrix and net structure can be recoreded with Raman spectrometer. Raman spectra of Ge-Ga-Te-NaI glass samples are seen in Fig. 4. Here, some peaks appear in the curves. There are three strong vibration peaks located around $65 \mathrm{~cm}^{-1}, 130 \mathrm{~cm}^{-1}, 156 \mathrm{~cm}^{-1}$ respectively. A very broad and low intensity vibration band locates near $220 \mathrm{~cm}^{-1}$. These vibration peaks or band are usually resulted from some bonds or atomic energy[15]. The first two vibration peaks are attributed to Ge-Te bonds while the peak at $155 \mathrm{~cm}^{-1}$ is ascribed to the vibration of Te-Te bonds[15-17]. The last vibration band may be due to Ge-Ge bonds[18]. From Fig. 4, the intensity of vibration peaks at $65 \mathrm{~cm}^{-1}, 130 \mathrm{~cm}^{-1}, 220 \mathrm{~cm}^{-1}$ were not affected with the increasing content of NaI. However, some subtle variations appeared at $155 \mathrm{~cm}^{-1}$ with the adding NaI. When the value of $x$ was between 5 and 15 , the vibration intensity at $155 \mathrm{~cm}^{-1}$ decreased little by little. What's more, when the content of $\mathrm{NaI}$ is above 15 at.\%, the vibration intensity enhanced gradually along with the content of $\mathrm{NaI}$ increasing. Some reasons can account for this phenomenon. The inherent 
structure of glass network which is mainly consist of $\mathrm{GaTe}_{3}$ triangle and $\mathrm{GeTe}_{4}$ tetrahedra was modified when $\mathrm{NaI}$ was introduced into the Ge-Ga-Te host glass. As is well known to all, iodine atom is considered to be a network terminator because it can trap the metallic electrons from tellurium atoms. As a result, Te-Te chains were split by iodine atoms and then new Te-I covalent bonds formed. Therefore, the vibration intensity of Te-Te bonds decreased when some contents of $\mathrm{NaI}$ were co-doped into Ge-Ga-Te glass. However, when too much NaI contents co-doped, many dissociative Te atoms may appear in the network. Due to its strong metallic, these dissociative $\mathrm{Te}$ atoms combined together as a form of Te-chain. Hence, the Te-Te bonds increased and the peak intensity at $159 \mathrm{~cm}^{-1}$ was strengthened.

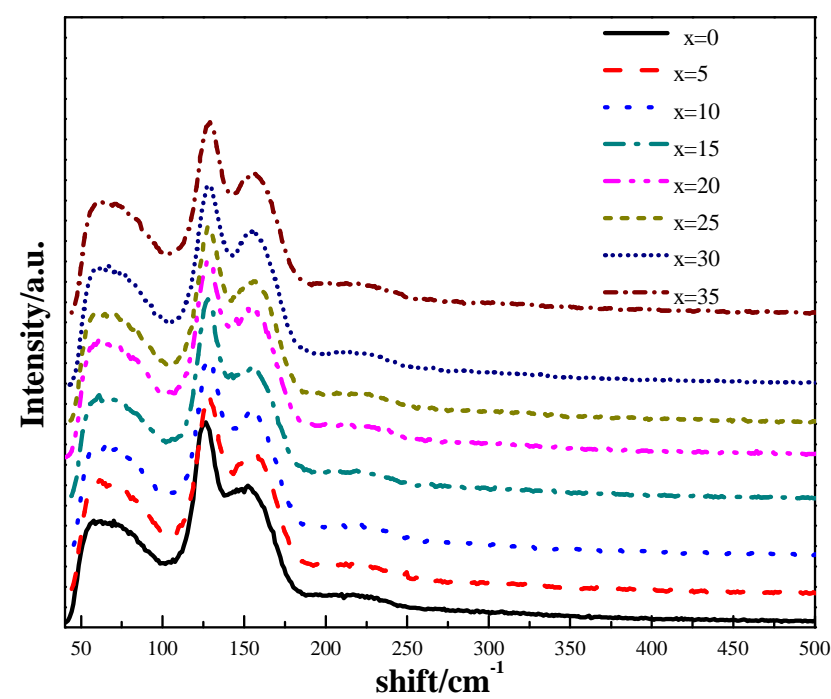

Fig. 4 The Raman graph of Ge-Ga-Te-NaI glass samples

\subsection{Near infrared absorption spectra and optical band gap analysis}

Fig. 5 shows the near infrared absorption spectra of Ge-GaTe-NaI glass samples. From the insert figure, the relationships between cut-off edge wavelength and $\mathrm{NaI}$ content are clear at a glance. When the content of $\mathrm{NaI}$ increased from 5 at.\% to 15 at.\%, the cut-off wavelength of these glasses shifts to the long-wavelength region. However, cut-off wavelength may shift to short-wavelength region as soon as $\mathrm{x}$ exceeds 15 . This may due to the electronegativity I doping into Ge-Ga-Te glass and new Te-I bonds formed. With the co-doping of NaI content, which was named as $\mathrm{x}$ (varing from5 at.\% to 15 at.\%), doping into glass, Te-Te chains were spilt from the glass network structure. Since the bond energy of Te-I $(198 \mathrm{~kJ} / \mathrm{mol})$ is lower than that of Te-Te bonds $(235 \mathrm{~kJ} / \mathrm{mol})$, the average bond energy of glass system decreased. Thus, cut-off wavelength had a red shift[19]. However, when $\mathrm{x}>15$ at.\%, from Raman spectra, the intensity of Te-Te bonds strengthened. It indicated that Te-Te bonds increased. So the average bond energy of glass system increased. As a result, cut-off wavelength had a blue shift. Eventually, the cut-off wavelengths of glass samples are located between $1645 \mathrm{~nm}$ and $1772 \mathrm{~nm}$. The lowest cut-off wavelength of glass samples is $1645 \mathrm{~nm}$ which is the smallest cut-off wavelength among the reported Te-based glasses doping alkali-halide[20, 21]. The specific values of cut-off wavelength are listed in Table 2. 


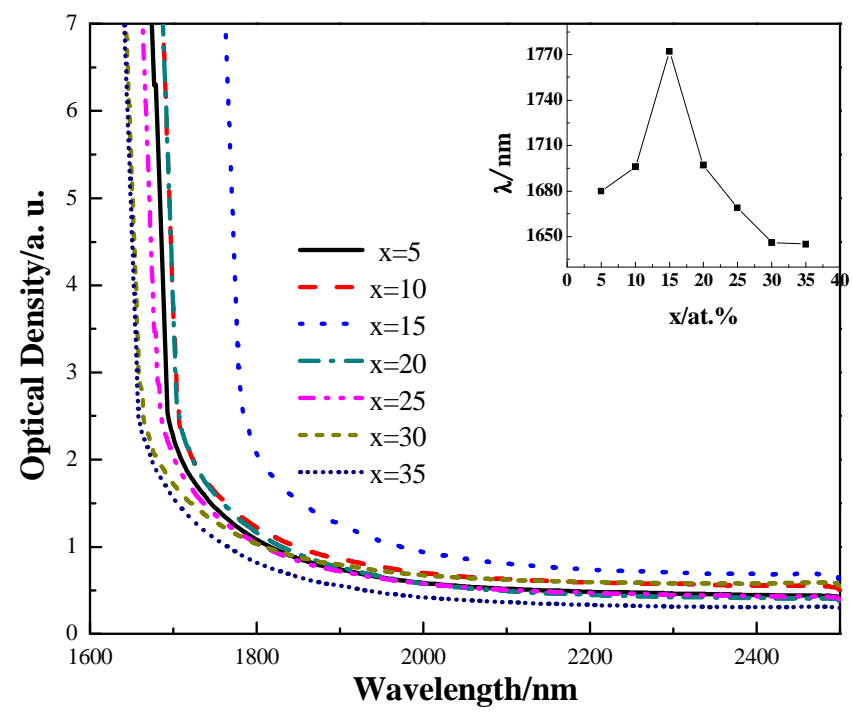

Fig. 5 Vis-IR absorption spectra of Ge-Ga-Te-NaI glass samples.Cut-off wavelengths with NaI increasing are shown in the insert figure)

The relationship between the absorption coefficient and the optical band-gap is given by the following equation:

$$
\alpha(\omega) \cdot \hbar \omega=B\left(\hbar \omega-E_{\text {opt }}\right)^{\mathrm{m}}
$$

where $\alpha(\omega)$ is the absorption coefficient, and it can be calculated by the function $\alpha=2.303 \mathrm{~A} / \mathrm{d}$ (A is the optical density of glass sample; $d$ is the thickness of testing glass sample); $\hbar$ is Plank constant, $\omega$ is the incident light angular frequency, $m$ is a parameter which determines the transition type of absorption edge. For amorphous materials, the direct allowed transition and indirect allowed transition are corresponding to $m=1 / 2$ and $m=2$ separately. $B$ is a constant about local state in the band gap. It can be calculated by the following equation:

$$
B=\frac{(4 \pi / c) \sigma_{0}}{n_{0} \Delta E}
$$

here, $\mathrm{c}$ is the light speed in vacuum, $\sigma_{0}$ is the electrical conductivity of absolute zero, $\mathrm{n}_{0}$ is the static refractive index, $\Delta \mathrm{E}$ is the local state tail width. Fig. 6 is corresponding to direct band gap, and the concrete values are listed in Table 2. The insert figure demonstrate that the optical gap decreased firstly with $\mathrm{x}$ values from 5 to 15 . However, the optical gap increased when $\mathrm{x}$ values exceeded 15. All this results fit well with the appearance of cut-off wavelength shift from red to blue on turn.. 


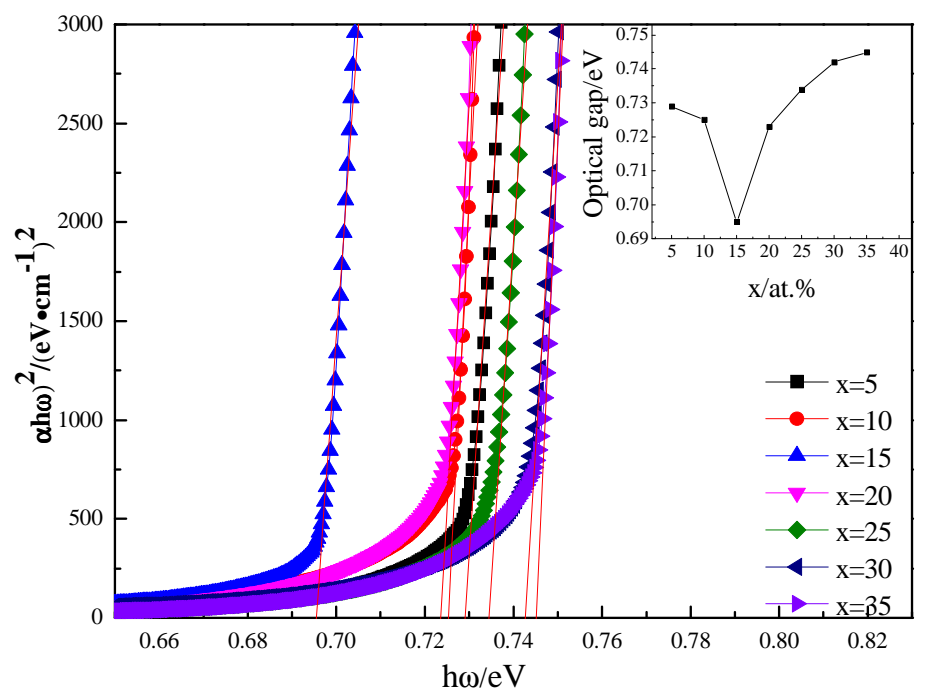

Fig. 6 The relationship between $(\alpha \bullet \hbar \omega)^{2}$ and $\hbar \omega$ for glass samples (relationships between direct band gap and NaI content are shown in the insert figure)

Table 2 Cut-off wavelength and direct band gap of Ge-Ga-Te-NaI glass samples

\begin{tabular}{cccc}
\hline x/at. $\%$ & Thickness/mm & Cut-off $\lambda(\mathbf{n m})$ & Direct-E Epp $_{\mathbf{m}} /(\mathbf{e V})$ \\
\hline 5 & 1.71 & 1680 & 0.729 \\
10 & 1.51 & 1696 & 0.725 \\
15 & 2.17 & 1772 & 0.695 \\
20 & 1.46 & 1697 & 0.723 \\
25 & 1.73 & 1669 & 0.734 \\
30 & 1.55 & 1646 & 0.742 \\
35 & 1.41 & 1645 & 0.745 \\
\hline
\end{tabular}

\subsection{Infrared spectra analysis}

The infrared transmission spectra of Ge-Ga-Te-NaI glass samples are shown in Fig. 7. All glass samples had a wide optical transmitting window from $2.5 \mu \mathrm{m}$ to $25 \mu \mathrm{m}$. $\left(\mathrm{Ge}_{15} \mathrm{Ga}_{10} \mathrm{Te}_{75}\right)_{70}(\mathrm{NaI})_{30}$ glass sample has the highest transmission ratio which can reach up to $52 \%$. The transmission of all glass samples plunged when wavelength was above $20 \mu \mathrm{m}$. This is attributed to the multi-phonon absorption which is produced by the Ge-Te bonds[11]. Some typical absorptions peaks existed in all curves. Two slight absorption peaks were respectively located at $6.3 \mu \mathrm{m}$ and $9.8 \mu \mathrm{m}$. The first and second absorption peaks are separately attributed to $\mathrm{H}_{2} \mathrm{O}$ molecule [22] and Si-O bonds[12] . Moreover, a wide absorption band was located between $15 \mu \mathrm{m}$ and $20 \mu \mathrm{m}$. The absorption band at 15-20 $\mu \mathrm{m}$ may be ascribed to some oxygen contamination such as $\mathrm{Ga}-\mathrm{O}$ or Ge-O bonds[23, 24]. To eliminate the absorption peaks which are caused by impurities especially oxygen impurities, some purification process need to be taken into account. Due to its excellent thermal property, $\left(\mathrm{Ge}_{15} \mathrm{Ga}_{10} \mathrm{Te}_{75}\right)_{85}(\mathrm{NaI})_{15}$ glass sample was chosen for the purification experiment. In the beginning, $300 \mathrm{ppm} \mathrm{Mg}$ co-doped into Te raw materials and then they were distilled into a $\mathrm{Ge}, \mathrm{Ga}, \mathrm{NaI}$ contained ampoule. Next, the steps were the same with traditional melt-quenching method. The spectra of $\left(\mathrm{Ge}_{15} \mathrm{Ga}_{10} \mathrm{Te}_{75}\right)_{85}(\mathrm{NaI})_{15}$ glass sample are presented in Fig. 8. In contrast to the unpurified glass sample, the purified $\left(\mathrm{Ge}_{15} \mathrm{Ga}_{10} \mathrm{Te}_{75}\right)_{85}(\mathrm{NaI})_{15}$ glass had a 
ulti-wide and ulti-flat optical transmitting window. Consequently, this purification method is considered to be a fine approach to reduce the content of impurities and eliminate the harmful effects resulted from the impurities.

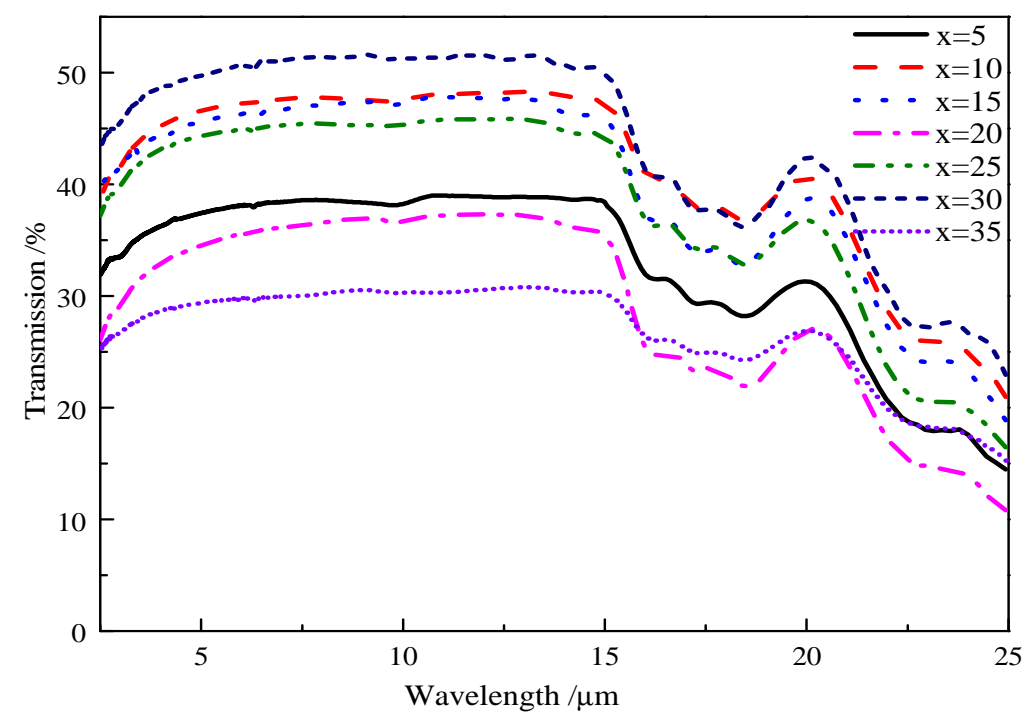

Fig. 7 Infrared transmission spectra of glass samples $\left(\left(\mathrm{Ge}_{15} \mathrm{Ga}_{10} \mathrm{Te}_{75}\right)_{100-\mathrm{x}}(\mathrm{CsBr})_{\mathrm{x}}\right)$

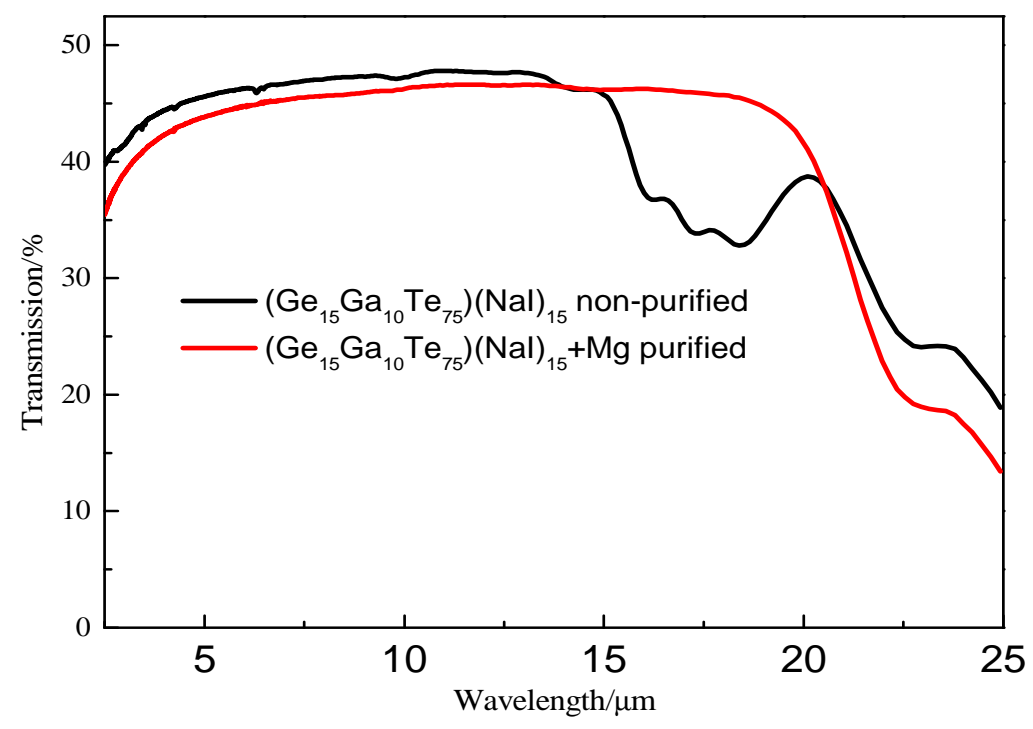

Fig. 8 Infrared spectra of $\left(\mathrm{Ge}_{15} \mathrm{Ga}_{10} \mathrm{Te}_{75}\right)_{80}(\mathrm{CsBr})_{20}$ glasses

\section{Conclusion}

In this study, a series of Ge-Ga-Te-NaI chalcogenide glasses were prepared and investigated. All glass samples have a wide infrared window and their infrared cut-off wavelengths are all above $25 \mu \mathrm{m}$. This glass system possesses good thermal characteristic because $\Delta \mathrm{T}$ values of all glass samples are greater than $100^{\circ} \mathrm{C}$. Especially, the glass of $\left(\mathrm{Ge}_{15} \mathrm{Ga}_{10} \mathrm{Te}_{75}\right)_{85}(\mathrm{NaI})_{15}$ has the highest $\Delta \mathrm{T}$ among other glass samples. What's more, it is $8^{\circ} \mathrm{C}$ greater than that of Ge-Ga-Te glass. 
The XRD patterns indicate that as much as 35 at.\% NaI content can be added into Ge-Ga-Te host glass and improve the glasses efficiently. The maximum direct band gap value is $0.745 \mathrm{eV}$. As a result, these excellent properties make the Ge-Ga-Te-NaI glasses potential materials for bio-optic sensors and ultra-wide spectrum infrared optical applications.

\section{Acknowledgments}

This work was financially supported by the Natural Science Foundation of China (Grant Nos. 61435009, 61177087, and 61377099), National Program on Key Basic Research Project (973 Program) (Grant No. 2012CB722703), International Science \& Technology Cooperation Program of China (Grant No. 2011DFA12040), Scientific Research Fund of Zhejiang Provincial Education Department (R1101263), Natural Science Foundation of Ningbo (Grant No. 2013A610118), Teaching and Research Award Program for Outstanding Young Teachers in Higher Education Institutions of MOE, P.R.C. Ningbo Optoelectronic Materials and Devices Creative Team (2009B21007), and Scientific Research Foundation of Graduate School of Ningbo University. This work was also sponsored by K. C. Wong Magna Fund of Ningbo University and the Outstanding (Postgraduate) Dissertation Growth Foundation of Ningbo University (Grant No. PY2014014).

\section{References}

1. Bahishti, A.A., et al., Effect of laser irradiation on thermal and optical properties of 
selenium-tellurium alloy. Journal of Non-Crystalline Solids, 2009. 355(45): p. 2314-2317.

2. Pamukchieva, V., et al., Evaluation of basic physical parameters of quaternary Ge-Sb-(S, Te) chalcogenide glasses. Journal of Non-Crystalline Solids, 2009. 355(50): p. 2485-2490.

3. Churbanov, M., et al., Stability of the optical and mechanical properties of chalcogenide fibers. Inorganic materials, 2002. 38(10): p. 1063-1068.

4. Elliott, G.R., et al., Chalcogenide glass microspheres; their production, characterization and potential. Optics Express, 2007. 15(26): p. 17542-17553.

5. Canciamilla, A., et al., Photo-induced trimming of coupled ring-resonator filters and delay lines in As $2 S 3$ chalcogenide glass. Optics letters, 2011. 36(2): p. 4002-4004.

6. Conseil, C., et al., Te-based chalcohalide glasses for far-infrared optical fiber. Optical Materials Express, 2012. 2(11): p. 1470-1477.

7. $\mathrm{Yu}, \mathrm{X} . \mathrm{B}$. , et al., Infrared spectrum estimation for maximum phonon energy in optical glasses. Journal of Dalian Polytechnic University, 2008. 27(6): p. 155-157.

8. Zhang, X., G. Fonteneau, and J. Lucas, Tellurium halide glasses. New materials for transmission in the 8-12 $\mu \mathrm{m}$ range. Journal of Non-Crystalline Solids, 1988. 104(1): p. 38-44.

9. Aldon, L., et al., Thermal stability of some glassy compositions of the Ge-As-Te ternary. Chalgogenide Letters, 2010. 7(10): p. 187-196.

10. Wilhelm, A.A., et al., Development of Far - Infrared - Transmitting Te Based Glasses Suitable for Carbon Dioxide Detection and Space Optics. Advanced Materials, 2007. 19(22): p. 3796-3800.

11. Danto, S., et al., A Family of Far - Infrared - Transmitting Glasses in the Ga - Ge - Te System for Space Applications. Advanced Functional Materials, 2006. 16(5): p. 1847-1852.

12. Wang, X.S., et al., Investigations of $\mathrm{Ge}-\mathrm{Te}-\mathrm{Agl}$ chalcogenide glass for far-infrared application. Spectrochimica Acta Part A: Molecular and Biomolecular Spectroscopy, 2012. 86(11): p. 586-589.

13. $\mathrm{Xu}, \mathrm{H}$. , et al., Glass formation and properties of Ge-Ga-Te-ZnI 2 far infrared chalcohalide glasses. Journal of Non-Crystalline Solids, 2014. 383: p. 212-215.

14. El-Sayed, S., et al., Physical evolution in network glasses of the Ag-As-Te system. Journal of Physics and Chemistry of Solids, 2007. 68(5): p. 1040-1045.

15. Sen, S., E. Gjersing, and B. Aitken, Physical properties of Ge $x$ As $2 x$ Te 100-3x glasses and Raman spectroscopic analysis of their short-range structure. Journal of Non-Crystalline Solids, 2010. 356(41): p. 2083-2088.

16. Kolobov, A.V., et al., Crystallization-induced short-range order changes in amorphous GeTe. Journal of Physics: Condensed Matter, 2004. 16(13): p. S5103.

17. Andrikopoulos, K.S., et al., Raman scattering study of GeTe and Ge2Sb2Te5 phase-change materials. Journal of Physics and Chemistry of Solids, 2007. 68(15): p. 1074-1078.

18. Fukunaga, T., Y. Tanaka, and K. Murase, Glass formation and vibrational properties in the (Ge, Sn) • system. Solid State Communications, 1982. 42(16): p. 513-516.

19. Fei, M., et al., First-principle study on the effect of high Pr doping on the optical band gap and absorption spectra of TiO 2. 2014.

20. $\mathrm{Xu}, \mathrm{H} . J$. , et al., Glass formation and properties of Ge-Ga-Te-Zn/2 far infrared chalcohalide glasses. Journal of Non-Crystalline Solids, 2014. 383(12): p. 212-215.

21. Wang, G., et al., Compositional dependence of the optical properties of novel Ge-Ga-Te-CSI far infrared transmitting chalcohalide glasses system. Journal of Physics and Chemistry of 
Solids, 2011. 72(1): p. 5-9.

22. Kanamori, T., et al., Chalcogenide glass fibers for mid-infrared transmission. Lightwave Technology, Journal of, 1984. 2(5): p. 607-613.

23. Zhang, S.Q., et al., Purification of Te75Ga10Ge15 glass for far infrared transmitting optics for space application. Optical Materials, 2010. 32(19): p. 1055-1059.

24. He, Y.J., et al., Glass formation and optical properties of Ge-Te-Ga-Cul far-IR transmitting chalcogenide glasses. Infrared Physics \& Technology, 2013. 60(18): p. 129-133. 